\title{
Small-scale spatial and temporal variation of life-history traits of common frogs (Rana temporaria) in sub-Arctic Finland
}

\section{Cogalniceanu, Dan}

2017-08

Cogalniceanu , D , Bancila , R I , Plaiasu , R , Rosioru, D \& Merila , J 2017 , ' Small-scale spatial and temporal variation of life-history traits of common frogs (Rana temporaria) in sub-Arctic Finland ' , Polar Biology , vol. 40 , no. 8 , pp. 1581-1592 . https://doi.org/10.1007/s00300-017-2081-8

http://hdl.handle.net/10138/307938

https://doi.org/10.1007/s00300-017-2081-8

unspecified

acceptedVersion

Downloaded from Helda, University of Helsinki institutional repository.

This is an electronic reprint of the original article.

This reprint may differ from the original in pagination and typographic detail.

Please cite the original version. 
1 Small-scale spatial and temporal variation of life history traits of common frogs (Rana temporaria) in sub-

2 Arctic Finland

5 Cogălniceanu $D^{1}$, Băncilă RI ${ }^{1,2}$, Plăiaşu $\mathrm{R}^{1,2}$, Roşioru $\mathrm{D}^{3}$, Merilä $\mathrm{J}^{4}$

6

$7 \quad{ }^{1}$ University Ovidius Constanţa, Faculty of Natural Sciences and Agricultural Sciences, Al. Universităţii 1, 8 corp B, 900740 Constanţa, Romania

92 “Emil Racoviţă” Institute of Speleology of Romanian Academy, 13 Septembrie Road, No. 13, 050711,

10 Bucharest, Romania

$11{ }^{3}$ National Institute for Marine Research and Development "Grigore Antipa", Blvd. Mamaia 300,

12 Constanţa, Romania

$13{ }^{4}$ University of Helsinki, Ecological Genetics Research Unit, Department of Biosciences, FI-00014

14 Helsinki, Finland

15

16 Corresponding author: Raluca I. Băncilă

17 “Emil Racoviţă” Institute of Speleology of Romanian Academy

1813 Septembrie Road, No. 13, 050711, Bucharest, Romania

19 Tel: + 40021 3188132; Fax: + 400213188132

20

21 e-mail: raluca.bancila@ieu.uzh.ch

22

23 


\section{Abstract}

29 Small-scale spatial and temporal variation in abiotic and biotic factors can cause variation in several major

30 life history traits in vertebrate ectotherms such as amphibians. However, relatively little is known about

31 small-scale variation in life history traits of sub-Artic amphibians. We studied the spatio-temporal

32 variation of adult life history traits linked to age and body size in the common frog (Rana temporaria)

33 from low (i.e., valley at $480 \mathrm{~m}$ a.s.1.) and high (i.e., hill at 530-650 m a.s.l.) altitude sites in the sub-Arctic

34 Kilpisjärvi area (Finland). Data on life history traits of frogs from hill sites collected during a three-year

35 field study were compared with previously published data from the valley sites. The results showed

36 spatio-temporal variation in life-history traits, frogs responding to spatio-temporal variation in the

37 environmental conditions with variation in age, life span, survival rates, body size and mass. Frogs from

38 hill sites had shorter life span, both in terms of mean age (5.6 versus 10.5 years) and longevity (9-10

39 versus 18 years), smaller snout-vent length (63 versus $77 \mathrm{~mm}$ ) and body mass (24 versus $45 \mathrm{~g})$ than frogs

40 from valley sites. The differences were more pronounced in females than in males indicating some sex-

41 specific responses to environmental differences among sites. The results show that small differences in

42 elevation (or elevation related abiotic and biotic factors) can translate to large differences in mean values

43 of important life history traits in common frogs living at the edge of their distribution range.

\section{$48 \quad$ Key words}

49 spatio-temporal variation, life history traits, skeletochronology, age structure 


\section{Introduction}

55 Geographic differentiation of life history traits and morphological features are of common occurrence in 56 both plants and animals (Mayr 1963; Endler 1977; Linhart and Grant 1996; Roff 1992). Local populations 57 at the limit of the species' range are thought to be under severe selection pressures to adapt and stay 58 adapted to harsh environmental conditions they face (e.g. Aitken et al. 2008; Hill et al. 2011). This can be 59 accomplished either through phenotypic plasticity, genetic adaptation, or both (Gienapp et al. 2008;

60 Moritz and Agudo 2013). Exploring these mechanisms that allow a species to persist in challenging 61 environments is crucial for understanding how species deal with ecological selection pressures (Merilä 62 and Hendry 2014; Ludwig et al. 2015).

63

64 Widely distributed species can be of particular interest in this context because: i) they experience variation 65 in climate, habitat and resource availability and quality over a wide geographic range; ii) their populations 66 inhabiting distinct locations experience different ecological and climatic pressures and iii) these different 67 selection pressures generate and maintain phenotypic differentiation in their life history traits (Bulgarella 68 et al. 2015; Miaud and Merilä 2001). Ectothermic animals like amphibians are very sensitive to 69 temperature as it influences directly their metabolism and sets limits to their distribution (Ludwig et al.

70 2015). Some temperate zone amphibians, such as the common frog (Rana temporaria), are widely 71 distributed and provide excellent models for studying age- and size-related life-history traits (and potential 72 trade-offs among them) across their wide latitudinal and altitudinal distribution range (Morrison and Hero 73 2003; Sinsch et al. 2015).

75 The common frog is considered to be a generalist anuran species in its habitat use (Van Buskirk and Arioli 76 2005) although other studies indicated habitat selectivity (Plăiaşu et al. 2010; Cogălniceanu et al. 2012). It

77 is a widespread species occurring throughout most of Europe from northern Spain through North Cape to

78 the Urals, and can be found at elevations ranging from sea level to 2,700 $\mathrm{m}$ a.s.1. To the south its 
79 distribution becomes patchy and increasingly restricted to mountainous regions (Kuzmin et al. 2009). Due

80 to its wide distribution range and high abundance, $R$. temporaria has been used as a model for testing a

81 variety of hypotheses of ecological and evolutionary interest (e.g. Miaud and Merilä 2001; Sinsch et al.

82 2015). Both larval and adult life history traits display extensive geographic variation (Miaud et al. 1999;

83 Miaud and Merilä 2001; Sinsch et al. 2015).

85 The common frog populations inhabiting Fennoscandia have been subject to several studies focused on 86 geographic variation along a latitudinal gradient. They have been used in testing Bergmann's rule in adult 87 body size (Laugen et al. 2005), validity of Allen's rule in leg lengths (Alho et al. 2011), as well as in 88 studies of variation in energy storage patterns (Jönsson et al. 2009) and testis weight (Hettyey et al. 89 2005). Furthermore, studies in sex chromosome differentiation (Rodrigues et al. 2014), genome size

90 variation (Matsuba and Merilä 2006), patterns of growth and age structure (Hjernquist et al. 2012),

91 plasticity in age and size at metamorphosis (Merilä et al. 2000), embryonic and larval development and

92 growth (Laugen et al. 2003; Merilä et al. 2004) have been conducted. They have also been subject to

93 studies in genetic variation and differentiation (Palo et al. 2003, 2004), presence of persistent organic

94 pollutants across Fennoscandia (ter Schure et al. 2002), larval nitrate tolerance (Johansson et al. 2001),

95 and effect of UV-B radiation on embryos (Pahkala et al. 2002).

97 Many studies have also focused on age structure, longevity and body size variation among common frog 98 populations (reviewed in: Miaud et al. 1999; Sinsch et al. 2015), but only few have focused on the small 99 scale (i.e. at population and metapopulation level) variations in age and size structure (but see: Elmberg 100 1990; Augert and Joly 1993; Ryser 1996). Two recent studies (Alho et al. 2008; Patrelle et al. 2012a) have 101 described the age structure of a common frog population living under extreme environmental conditions at 102 the limit of species distribution range in the sub-Arctic Finland at $480 \mathrm{~m}$ a.s.l. Common frogs in this area 103 occur also at altitudes higher than this, and a recent study discovered that microclimatic factors are 
104 important determinants of species occurrence in this area (Blank et al. 2014). However, little is known

105 about the life history of the common frogs inhabiting the high altitude sites in this area.

106

107 The aim of the present study was to compare adult life history traits related to age and size of common

108 frogs from low ("valley" at $480 \mathrm{~m}$ a.s.1.) and nearby high ("hill" at 530-650 $\mathrm{m}$ a.s.1.) altitude sites in the 109 sub-Artic Kilpisjärvi area.

\section{Materials and methods}

\section{Study area}

115 The study area was located at Kilpisjärvi $\left(69^{0} 03^{\prime} \mathrm{N}, 20^{0} 50^{\prime} \mathrm{E}\right)$, in the northwestern corner of Finland, 270

$116 \mathrm{~km}$ north of the Arctic Circle and ca $50 \mathrm{~km}$ south-east of the Arctic Ocean. The climate in the area lies 117 between the North Atlantic oceanic climate and the Eurasian continental climate, with a mean annual 118 temperature of $-2.0^{\circ} \mathrm{C}$. The area experiences a large variation in solar radiation: in winter the sun is below 119 the horizon for 55 days, while in summer there is no sunset for 62 days (Kauhanen 2013). The duration of 120 the growth season varies between 69-132 days (mean 101 days;

121 http://www.helsinki.fi/kilpis/english/Climate/records.htm; Järvinen 1987). The area resides about $100 \mathrm{~km}$

122 north of the continuous coniferous forest and belongs to the sub-alpine birch forest zone (Betula 123 pubescens) at low altitudes (480-600 m). Above $600 \mathrm{~m}$, the area is alpine tundra (Järvinen and Partanen 124 2008; Kauhanen 2013). Frogs in the area appear to be free of chytrid fungus (Patrelle et al. 2012b).

\section{Data collection in the field}

127 To obtain data for the high elevation sample (henceforth: hill-site), fieldwork was done during the 128 summers of 2003 (9-28 August), 2009 (6-12 July) and 2010 (10-18 August) in the Malla nature reserve 129 and the south-western slope of the Saana Mountain (Fig. 1). Adult animals were collected along transects 
130 and data on 134 (81 females and 53 males) individuals were obtained. The captured animals were

131 measured on site: body size was measured as the length from snout to vent (snout-vent length, SVL) to the

132 nearest $0.1 \mathrm{~mm}$ using a dial caliper. Body mass was recorded with an electronic balance (Triton T2 400),

133 with a precision of $0.01 \mathrm{~g}$. The animals were photographed and the second toe of the left arm was cut

134 below the second phalange and stored in alcohol. The animals were then released at the site of capture.

135 The exact location and altitude of the animals was taken with a hand-held Garmin GPS-tracker. Toes from

136 at least 20 juveniles were also collected each year as they were required for calibration in

137 skeletochronology (see below).

139 To obtain data for the low elevation sample (henceforth: valley-site), we re-used data from Patrelle et al.

140 (2012a) which consisted of 169 adult frogs (116 females and 53 males) collected in the valley between the

141 Malla and the Saana mountains (the distance separating the valley site and the hill sites is about $5 \mathrm{~km}$ )

142 (Fig. 1). The raw data consisted of 699 individual measures (captures and recaptures) in different years.

143 Excluding multiple recaptures from the same year, there were 397 unique captures during the five study

144 years (1999-2003). Thus, recaptured individuals were considered repeatedly, in all years of capture or

145 recapture, with SVL and body mass measured each time (if multiple recaptures in a single year, the latest

146 date was considered), and age corrected based on the year of measurement. Animals were captured in late

147 summer in the hill-site (i.e. post reproduction season) whereas in valley-site the captures took place in the

148 early spring (i.e. pre-breeding and breeding season).

150 Skeletochronology

151 Age related parameters were estimated through skeletochronology sensu Castanet and Smirina (1990),

152 using some modifications following Rozenblut and Ogielska (2005). Skeletochronology allows for the

153 reliable estimation of age of individuals in most populations and species (Sinsch 2015), limited only in the

154 correct assessment of age in old individuals (Wagner et al. 2011). In brief, the second phalange was

155 decalcified for $3 \mathrm{~h}$ with $5 \% \mathrm{HNO}_{3}$, followed by inclusion in TissueTek, freezing and sectioning with a 
156 Tehsys CR 3000 cryotome at $16 \mu \mathrm{m}$. The cross sections were stained with Ehrlich's haematoxylin for 3

157 hrs and photographed thereafter using an Olympus CX 31 microscope and Quick Photo Micro 2.3

158 software. We estimated age from the Lines of Arrested Growth (LAGs), after correction for resorption in

159 older individuals by using cross sections from juveniles and subadults as recommended by Hemelaar

160 (1985), Castanet and Smirina (1990), and Rozenblut and Ogielska (2005). Three independent observers

161 (RP, DR and DC) counted the lines of arrested growth (LAGs) in 2-6 sections per individual.

163 The distance between two LAGs is an indicator of individual growth in a given age, and a pattern of

164 decreasing intervals between LAGs after a few years is thought to indicate the onset of sexual maturity,

165 with resources being reallocated from growth to reproduction (Smirina 1994). We inferred the age of

166 sexual maturity from the bone growth pattern as indicated by Smirina (1994), and in addition compared

167 with the youngest adult age class in our sample, considered as the minimal age of sexual maturity. Age

168 was assessed in a similar way in the valley site (Patrelle et al. 2012a), except for endosteal resorption that

169 was based on a method developed by Alho (2004). Since frogs in the valley were collected from breeding

170 sites, all individuals were mature and age of sexual maturity was estimated as the minimum age in the

171 sample (Patrelle et al. 2012a). Although slightly different approaches were used to account for endosteal

172 resorption in hill and valley datasets, this is unlikely to have influenced age assessment.

174 Data analyses

175 We analyzed data from both the valley sites collected during five consecutive years (1999-2003; Patrelle 176 et al. 2012a), and from the hill sites at three different time points (2003, 2009 and 2010). We computed a 177 sexual dimorphism index (SDI) for SVL, body mass and average age, with the results arbitrarily defined 178 as positive when females are the larger sex and negative in the converse situation (Lovich and Gibbons 179 1992) despite criticisms on using this method (see Ranta et al. 1994) since it allows to compare all three 180 parameters: 


$$
S D I=\frac{\text { Mean }_{\text {size }} \text { larger sex }}{\text { Mean size } e_{\text {smaller sex }}}
$$

184 The average (minimum) age of maturation $\left(A_{\text {mat }}\right)$ is the average number of growing seasons experienced

185 before size at sexual maturity is reached. Longevity $\left(A_{\max }\right)$ is the highest recorded age.

187 We fitted growth curves based on the von Bertalanffy growth function

$$
L_{t}=L_{\infty}\left(1-e^{-k\left(t-t_{0}\right)}\right)
$$

191 with the FSA package in R (Ogle 2010), where $L_{t}$ is the body size at age $t$ (or after $t$ growing seasons

192 experienced), $L_{\infty}$ is the estimated asymptotic body size, $k$ is a growth coefficient relating the rate of decline

193 in growth as individuals attain maximum body size (units $\operatorname{are~year}^{-1}$ ), and $t_{0}$ is the age at metamorphosis.

194 Differences between sites and sex-specific growth rates were tested using a likelihood ratio test (Kimura 195 1980) using package fishmethods in R (Nelson 2014).

197 Adult survival rate was calculated according to Robson and Chapman's (1961, in Krebs 1989) formula: $S$ $198=T / \sum N+T-1$ with the fishmethods package. Here, $S$ is the average finite survival rate, $T$ is the sum of the 199 coded ages times their frequencies when age is found by setting the youngest included age-class to 0 , the 200 next age to 1 and so forth $T=O N_{x}+1 N_{x+1}+2 N_{x+2}+\ldots i N_{x+\mathrm{i}} ; \sum N$ is the number of animals from age-class $x$ to $201 x+1=N_{x}+N_{x+1}+N_{x+2}+\ldots+N_{x+i}$; and $N_{x}$ is the number of individuals in age-class $x$. This formula is only 202 valid for stationary populations in which recruitment and survival are relatively constant. As these 203 assumptions are rarely met in nature, calculated values should be seen as relative estimates allowing only 204 for comparisons between sexes and sites (Schabetsberger and Goldschmid 1994). We note that for the 205 valley site, the assumption about similar survival rates between sexes has been verified (Alho et al. 2008). 
206 Growth rate $(R)$ can be calculated with the following equation: $R=d L / d t=k \times\left(L_{\infty}-L_{t}\right)$, which is 207 maximal when $L_{t}$ is minimal.

208

209 SVL and body mass were modeled as a function of site, sex, year and age using general additive Mixed

210 Models (GAMMs) which enable individual effects to be accommodated in analyses, thus accounting for

211 non-independence among individuals at the same site or year. The 'mgcv' package (Wood 2006) was used

212 to fit the models to the data in R. Pairwise comparisons between site, sexes and years were made using the

213 R multcomp package (Hothorn et al. 2008).

216 Results

218 All the age, size and growth related parameters are summarized in Table 1. There were significant 219 differences in body size between sites, sexes and years (Table 2). Frogs were significantly larger and 220 heavier in the valley as compared to the hill site (Table 3, Appendix 1). Females were significantly 221 heavier, but not significantly larger in SVL than males (Table 4). Significant differences in body size were observed also among years (Table 2, Appendix 1).

224 Females from the hill site were significantly smaller and lighter compared to females from the valley site (Table 3, Fig. 2A, B): on average females from the hill-site had $78 \%$ and $47 \%$ of the SVL and body mass

226 of the valley females, respectively. Likewise, males from the hill site were smaller and lighter compared 227 with males from the valley site (Table 3, Fig. 2A, B, Appendix 1): on average, the hill-site males had 90\% 228 and $66 \%$ of the SVL and body mass of valley males, respectively. In both sexes, SVL and body mass were 229 significantly correlated within each of the sites (Table 4). The regression equations for females had very 230 similar slopes but different intercept values, indicating the females from the hill site had a smaller body 231 mass compared with females from the valley site for the same body length value (Table 4). 
233 The degree of SDI for SVL and body mass varied between the sexes in both sites: in the valley site

234 females were larger $\left(\mathrm{SDI}_{\mathrm{SVL}}=1.08\right)$ and heavier $\left(\mathrm{SDI}_{\mathrm{body}}\right.$ mass $\left.=1.23\right)$, while in the hill site males were

235 larger $\left(\mathrm{SDI}_{\mathrm{svL}}=-1.05\right)$ and heavier $\left(\mathrm{SDI}_{\mathrm{body} \text { mass }}=-1.14\right)$. The sex ratio was biased in both sites, with

236 females being more abundant. The sex ratio (males: females) in the hill site was 0.65 (53:81), significantly

237 higher as compared to the valley site $0.45(53: 116)$ (chi-square $=3.942, d . f .=1, p=0.047)$. The SDI for

238 mean age showed that females were older in both sites, but the differences between sexes were much

239 larger in the valley population (valley: $\mathrm{SDI}_{\text {mean age }}=1.39 ;$ hill: $\mathrm{SDI}_{\text {mean age }}=1.08$ ).

241 Both females and males from the valley site were significantly older than individuals from the hill site

242 (Table 3, Fig. 2C, Appendix 1). Individuals from the hill site had an average age of only 50\% in the case

243 of females and $64 \%$ for males, compared to those in the valley site.

245 The growth curves were significantly different between the hill and valley sites (Table 5, Fig. 3) although

246 there were no significant differences between any of the Von Bertalanffy parameters. Females and males

247 showed significantly different growth curves (Table 5, Fig. 4) driven by significant differences in $t_{0}(p$

$248<0.001)$ and growth coefficient $(p=0.039)$. Differences in $L_{\infty}$ were substantial, but not significant $(p=$

249 0.89). In both hill and valley sites frogs showed an evident increase in body length and body mass (Table

250 2, Fig. 2A - C) but frogs reached an asymptote in length and body mass only in hill site (Fig. 4A, B).

252 Age structure differed between sites and sexes (Fig. 5, Appendix 1). For the hill site the most abundant 253 age class for both females and males was 6 years old (48\% of females and $34 \%$ of males). There are 254 differences among years in the age structure, with a decrease in age composition in 2009 compared to 255 2003, followed by an increase from 2009 to 2010 (Fig. 6). For valley site, the proportion of females 10 256 years old (23\%) was the highest, whereas the highest proportion (28\%) of males were five year old (Fig. 257 5). 
258 The lower average age of the frogs on the hill site is supported by the fact that none of the 258 individuals 259 toe-clipped in 2003 were recaptured in 2009. In $201019 \%$ of the individuals marked in 2009 were 260 recaptured (14 individuals out of 143 captures, not including the 25 freshly metamorphosed individuals).

\section{Discussion}

Our study revealed significant differences in common frog life-history traits, including life span, survival,

266 body size and mass over short spatial and temporal scales. Individuals from the hill site had shorter life

267 span, both in terms of mean age and longevity, smaller body size and body mass than those from the

268 valley-site. These differences were more pronounced in females as compared to males. Males were larger

269 and heavier than females in the hill than in the valley site indicating that females were more affected by

270 factor(s) associated with higher altitude conditions than males. The individuals from the hill site exhibited

271 strong interannual variation in body mass and length, but mostly in the former, and also in age structure.

272 In the following, we discuss these findings in relation to what is known about common frog life history 273 trait differentiation, in particular, in relation to environmental gradients.

274 Studies of neighboring populations at small spatial scale often are focused on local ecological conditions 275 as the main explanation for the observed differences (Miaud and Merilä 2001). A recent review (Sinsch et 276 al. 2015) found that common frogs at higher altitudes and latitudes (i.e. experiencing adverse conditions) 277 reached reproductive maturity at significantly older ages and enjoyed an increased longevity as well. Our 278 results support this finding only for the valley site frogs. This finding is at odds with Miaud et al. (1999),

279 who showed that under adverse conditions $R$. temporaria grows older and larger, with sexual size 280 dimorphism increasing with climatic harshness, due to slower juvenile growth rate and a delayed maturity 281 in females. One possible explanation for this difference is that conditions at the hill-site are so adverse that 282 common frogs there never reach very old ages and sizes. 
283 The hill sites are likely to be harsher environments than the valley sites as ambient temperatures drop with 284 altitude on average $0.9^{0} \mathrm{C}$ with every $100 \mathrm{~m}$ increase in altitude (Järvinen 1989), exposure to winds 285 becomes higher, and vegetation cover is reduced (Kauhanen 2013). Because of the latter, also exposure to 286 predation by birds and mammals is likely to increase. Likewise, lower invertebrate prey abundance should 287 make finding food more difficult in the hill as compared valley sites. All these coupled with the slightly 288 shorter growth season in the hill than in valley sites should impose constraints on growth, development 289 and survival (Muir et al. 2014). In contrast, although day length is the most accurate and consistent 290 environmental cue in northernmost seasonal environments (Saikkonen et al. 2012), and has a major 291 influence on mean age, age at first reproduction and longevity in common frog (Hjernquist et al. 2012), it 292 cannot explain the life history trait differentiation between hill and valley sites situated just a few 293 kilometers apart.

295 Temperature has a strong effect on the development and growth of most living organisms (Marchand 296 2014). A larger body size and lower growth rates in adults are adaptive in colder environments (Angilletta 297 et al. 2004), and are probably coupled with higher metabolic rates required to sustain activity during the 298 shorter growing season and lower predation risk. To reach the large body size in a cold environment, individuals must prolong growth period and delay reproduction relative to those in warm environments.

300 Such delayed maturation is adaptive when larger body size favors an increase in fecundity and/or survival rates (Stearns 1992; Angilletta et al. 2004). Contrary to Bergmann's rule, body size variation in adult common frogs is not linearly related to latitude (or altitude), but covaries with age as expected for a 303 species that grows indeterminately (Laugen et al. 2005; Sinsch et al. 2015). This indicates that variation in 304 common frog body size mirrors differences in age structure. Thus, the finding that individuals from the 305 hill sites had lower age and smaller body size than those from the valley-sites fits with this idea. However, 306 an alternative explanation for age (and size) differences between hill and valley relates to how the data 307 from the contrasting sites were collected. Since the hill sites were sampled in the late summer and valley 308 sites in early summer, the hill samples may include more subadults than the valley samples which were all 
309 breeding adults. However, we believe this in an unlikely explanation for the observed differences because

310 the differences in body size persisted even after controlling for age difference among sites.

312 We discovered that the population sex ratio differed significantly between the hill and valley site, with

313 stronger bias towards females in the valley than in the hill site. The strong female bias in the valley

314 population is known since earlier (Alho et al. 2008, 2010), with on average, only one third of breeding

315 individuals being males. The cause of this sex-bias is thought be environmentally induced sex reversal for

316 which evidence has been accumulating (Perrin 2009; Matsuba et al. 2010; Rodrigues et al. 2016). The

317 reason why the sex bias is less pronounced in the hill site than in the valley site is not obvious, but this

318 difference can be related to differences in environmental conditions experienced by maturing individuals.

319 Likewise, an earlier study has confirmed that males and females in the valley site do not differ in their

320 survival rates (Alho et al. 2008). Hence, the differences in sex ratio among valley and hill sites are

321 unlikely to depend on sex differences in mortality.

323 In conclusion, the results demonstrate marked differences in common frog key life history traits between

324 ecologically contrasting environments in the sub-Arctic. The frogs inhabiting the environmentally more

325 adverse hill sites are younger and smaller than those inhabiting valleys. As these findings go against the

326 large-scale patterns showing that common frogs tend to get older with increasing environmental adversity

327 (Miaud et al. 1999; Sinsch et al. 2015), the results highlight the importance of scale in ecology (Schneider 328 2001): downscaling large scale patterns may be of limited validity.

\section{Acknowledgements}

333 Fieldwork was made possible thanks to three grants from Lapland Biosphere-Atmosphere Facility Finland

334 Programs Lapbiat (2003) and Lapbiat 2 (2009 and 2010), funded by the EU. Collecting permits were 
335 provided by Lapland Regional Environmental Center (permit no. LAP-2009-L-356-254) and Lapland 336 Center for Economic Development, Transport and the Environment (permit no. 337 LAPELY/926/07.01.2010). The skeletochronological procedure was approved by the Ethics Committee of 338 the Faculty of Natural and Agricultural Sciences, Ovidius University, Constanţa on 19.06.2013. Special 339 thanks to Ruşti Dorel, Dr. Ioan Ghira, Jianu Claudia and Dr. Tudor Marian for their help with fieldwork,

340 to Dr. Tibor Kovacs for the valuable advice and support during the fieldwork, and to Dr. Antero Järvinen 341 that provided constant support and advice.

\section{References}

346 Aitken SN, Yeaman S, Holliday JA, Wang T, Curtis-McLane S (2008) Adaptation, migration or 347 extirpation: climate change outcomes for tree populations. Evol Appl 1:95-111. doi:10.1111/j.1752$348 \quad 4571.2007 .00013 . x$

Alho JS (2004) Population biology of the common frog in subarctic. MSc Thesis, University of Helsinki temporaria). Mol Ecol 19:1763-1773. doi: 10.1111/j.1365-294X.2010.04607.x

358 Alho JS, Herczeg G, Laugen AT, Räsänen K, Laurila A, Merilä J (2011) Allen's rule revisited: 359 quantitative genetics of extremity length in the common frog along a latitudinal gradient. J Evol Biol 360 24:59-70. doi: 10.1111/j.1420-9101.2010.02141.x 
362 Angilletta Jr. MJ, Steury TD, Sears MW (2004) Temperature, growth rate and body size in ectotherms:

363 fitting pieces of a life history puzzle. Integr Comp Biol 44:498-509. doi: 10.1093/icb/44.6.498

365 Augert D, Joly P (1993) Plasticity of age at maturity between two neighbouring populations of the 366 common frog (Rana temporaria L.). Can J Zool 71:26-33. doi: 10.1139/z93-005

368 Blank L, Luoto M, Merilä J (2014) Potential effects of climate change on the distribution of the common 369 frog Rana temporaria at its northern range margin. Isr $\mathrm{J}$ Ecol Evol 59:130-140. 370 doi:10.1080/15659801.2014.888825

372 Bulgarella M, Trewick SA, Godfrey AJR, Sinclair BJ, Morgan-Richards M (2015) Elevational variation in 373 adult body size and growth rate but not in metabolic rate in the tree weta Hemideina crassidens. J Insect 374 Physiol 75:30-38. doi: 10.1016/j.jinsphys.2015.02.012

375

376 Castanet J, Smirina E (1990) Introduction to the skeletochronological method in amphibians and reptiles.

377 Ann Sci Nat Zool (Paris) 11:191-196

379 Cogălniceanu D, Băncilă R, Plăiaşu R, Samoilă C, Hartel T (2012) Aquatic habitat used by amphibians

380 with specific reference to Rana temporaria at high elevations (Retezat Mountains National Park, 381 Romania). Ann Limnol - Int J Lim 48:355-362. doi:10.1051/limn/2012026

383 Elmberg J (1990) Long-term survival, length of breeding season, and operational sex ratio in a boreal 384 population of common frogs, Rana temporaria L. Can J Zool 68:121-127. doi: 10.1139/z90-017 
386 Endler JA (1977) Geographic variation, speciation, and clines (No. 10). Princeton University Press,

387 Princeton

388

389 Gienapp P, Teplitsky C, Alho JS, Mills JA, Merilä J (2008) Climate change and evolution: disentangling 390 environmental and genetic responses. Mol Ecol 17:167-178. doi:10.1111/j.1365-294X.2007.03413.x

391

392 Hemelaar ASM (1985) An improved method to estimate the number of year rings resorbed in phalanges

393 of Bufo bufo and its application to populations from different latitudes and altitudes. Amphib-Reptilia

394 6:343-353. doi: 10.1163/156853885X00326

395

396 Hettyey A, Laurila A, Herczeg G, Jönsson KI, Kovács T, Merilä J (2005) Does testis weight decline

397 towards the Subarctic? A case study on the common frog, Rana temporaria. Naturwissenschaften 92:188-

398 192. doi: 10.1007/s00114-005-0607-3

399

400 Hill JK, Griffiths HM, Thomas CD (2011) Climate change and evolutionary adaptations at species' range 401 margins. Annu Rev Entomol 56:143-159. doi: 10.1146/annurev-ento-120709-144746

402

403 Hjernquist MB, Söderman F, Jönsson KI, Herczeg G, Laurila A, Merilä J (2012) Seasonality determines 404 patterns of growth and age structure over a geographic gradient in an ectothermic vertebrate. Oecologia 405 170:641-649. doi: 10.1007/s00442-012-2338-4

406

407 Hothorn T, Bretz F, Westfall P (2008) Simultaneous inference in general parametric models. Biom J 408 50:346-363. doi: 10.1002/bimj.200810425

409

410 Järvinen A (1987) Basic climatological data on the Kilpisjärvi area, NW Finnish Lapland. Kilpisjärvi 411 Notes 10:1-16 
413 Järvinen A (1989) The life history of Ranunculus glacialis, an Arctic-Alpine perennial herb, in Finnish 414 Lapland. Holarctic Ecol 12:152-62. doi: 10.1111/j.1600-0587.1989.tb00834.x

416 Järvinen A, Partanen R (2008) Stand dynamics of mountain birch, Betula pubescens ssp. czerepanovii 417 (Orlova) Hämet-Ahti in NW Finnish Lapland. Kilpisjärvi Notes 21:6-13

419 Johansson M, Räsänen K, Merilä J (2001) Comparison of nitrate tolerance between different populations 420 of the common frog, Rana temporaria. Aquat Toxicol 54:1-14. doi:10.1016/S0166-445X(00)00182-x

422 Jönsson KI, Herczeg G, O'Hara RB, Söderman F, Ter Schure AF, Larsson P, Merilä J (2009) Sexual 423 patterns of prebreeding energy reserves in the common frog Rana temporaria along a latitudinal gradient.

424 Ecography 32:831-839. doi: 10.1111/j.1600-0587.2009.05352.x

425

426 Kauhanen HO (2013) Mountains of Kilpisjärvi host an abundance of threatened plants in Finnish Lapland.

427 Bot Pac 2:43-52. doi: 10.17581/bp.2013.02105

Kimura DK (1980) Likelihood methods for the von Bertalanffy growth curve. US Fish Bull 77:765-776

431 Krebs CJ (1989) Ecological methodology. Harper and Row, New York

433 Kuzmin S, Ishchenko V, Tuniyev B, Beebee T, Andreone F, Nyström P, Anthony B, Schmidt B, 434 Ogrodowczyk A, Ogielska M, Bosch J, Miaud C, Loman J, Cogălniceanu D, Kovács T, Kiss I (2009) 435 Rana temporaria. The IUCN Red List of Threatened Species. Version 2014.3. <www.iucnredlist.org>. 436 Accessed 11 March 2015 
438 Laugen AT, Laurila A, Jönsson I, Söderman F, Merilä J (2005) Do common frogs (Rana temporaria)

439 follow Bergmann's rule? Evol Ecol Res 7:717-731

440

441 Laugen AT, Laurila A, Merilä J (2003) Latitudinal and temperature-dependent variation in embryonic

442 development and growth in Rana temporaria. Oecologia 135:548-554. doi: 10.1007/s00442-003-1229-0

443

444 Linhart YB, Grant MC (1996) Evolutionary significance of local genetic differentiation in plants. Annu

445 Rev Ecol Syst 27:237-277. doi: 10.1146/annurev.ecolsys.27.1.237

446

447 Lovich JE, Gibbons JW (1992) A review of techniques for quantifying sexual size dimorphism. Growth 448 Dev Aging 56:269-281

449

450 Ludwig G, Sinsch U, Pelster B (2015) Behavioural adaptations of Rana temporaria to cold climates. J

451 Therm Biol 49:82-90. doi: 10.1016/j.jtherbio.2015.02.006

452

453 Marchand PJ (2014) Life in the cold: an introduction to winter ecology. University Press of New England,

454 Lebanon, New Hampshire

455

456 Matsuba C, Merilä J (2006) Genome size variation in the common frog Rana temporaria. Hereditas 457 143:155-158. doi: 10.1111/j.2006.0018-0661.01919.x

458

459 Matsuba C, Alho JS, Merilä J (2010) Recombination rate between sex chromosomes depends on 460 phenotypic sex in the common frog. Evolution 64:3634-3637. doi: 10.1111/j.1558-5646.2010.01076.x 461

462 Mayr E (1963) Animal species and their evolution. Belknap Press, Harvard 463 
464 Merilä J, Laurila A, Laugen AT, Räsänen K, Pahkala M (2000) Plasticity in age and size at 465 metamorphosis in Rana temporaria - comparison of high and low latitude populations. Ecography 466 23:457-465. doi: 10.1111/j.1600-0587.2000.tb00302.x

468 Merilä J, Laurila A, Lindgren B (2004) Variation in the degree and costs of adaptive phenotypic plasticity 469 among Rana temporaria populations. J Evol Biol 17:1132-1140. doi: 10.1111/j.1420-9101.2004.00744.x

471 Merilä J, Hendry AP (2014) Climate change, adaptation, and phenotypic plasticity: the problem and the 472 evidence. Evol Appl 7:1-14. doi: 10.1111/eva.12137 temporaria (Amphibia: Anura): a literature review and new data from the French Alps. J Zool 249:61-73. doi: 10.1111/j.1469-7998.1999.tb01060.x

478 Miaud C, Merilä J (2001) Local adaptation or environmental induction? Causes of population differentiation in alpine amphibians. Biota 2:31-50

480

481 Moritz C, Agudo R (2013) The future of species under climate change: resilience or decline? Science 482 341:504-508. doi: 10.1126/science.1237190

484 Morrison C, Hero JM (2003) Geographic variation in life-history characteristics of amphibians: a review. 485 J Anim Ecol 72:270-279. doi: 10.1046/j.1365-2656.2003.00696.x 488 adaptation to altitude in the common frog (Rana temporaria). Mol Ecol 23:561-574. doi: $489 \quad 10.1111 /$ mec. 12624 
491 Nelson GA (2014) Package 'fishmethods' in R.

492 http://cran.rproject.org/web/packages/fishmethods/fishmethods.pdf. Accessed 20 March 2015

493

494 Ogle DH (2010) FSA - package in R. http://www.rforge.net/FSA/index.html. Accessed 20 March 2015

496 Pahkala M, Laurila A, Merilä J (2002) Effects of ultraviolet-B radiation on common frog Rana temporaria 497 embryos from along a latitudinal gradient. Oecologia 133:458-465. doi: 10.1007/s00442-002-1058-6

498

499 Palo JU, O'Hara RB, Laugen AT, Laurila A, Primmer CR, Merilä J (2003) Latitudinal divergence of 500 common frog (Rana temporaria) life history traits by natural selection: evidence from a comparison of 501 molecular and quantitative genetic data. Mol Ecol 12:1963-1978. doi: 10.1046/j.1365-294X.2003.01865.x

503 Palo JU, Schmeller DS, Laurila A, Primmer CR, Kuzmin SL, Merilä J (2004) High degree of population 504 subdivision in a widespread amphibian. Mol Ecol 13:2631-2644. doi: 10.1111/j.1365-294X.2004.02269.x 505

506 Patrelle C, Hjernquist MB, Laurila A, Söderman F, Merilä J (2012a) Sex differences in age structure, 507 growth rate and body size of common frogs Rana temporaria in the subarctic. Polar Biol 35:1505-1513. 508 doi:10.1007/s00300-012-1190-7

510 Patrelle C, Miaud C, Cristina N, Kulberg P, Merilä J (2012b) Chytrid fungus screening in a population of 511 common frogs from Northern Finland. Herpetol Rev 43:422-425

513 Perrin N (2009) Sex reversal: a fountain of youth for sex chromosomes? Evolution 63:3043-3049. doi: $514 \quad 10.1111 / \mathrm{j} .1558-5646.2009 .00837 . x$ 
516 Plăiaşu R, Băncila RI, Cogălniceanu D (2010) Body size variation in Rana temporaria populations

517 inhabiting extreme environments. Ovidius Univ Ann Nat Sci Biol Ecol Ser 14:121-126

518

519 Ranta E, Laurila A, Elmberg J (1994) Reinventing the wheel: analysis of sexual dimorphism in body size.

520 Oikos 70:313-321. doi: 10.2307/3545768

521

522 Rodrigues N, Merilä J, Patrelle C, Perrin N (2014) Geographic variation in sex-chromosome 523 differentiation in the common frog (Rana temporaria). Mol Ecol 23:3409-3418. doi: 10.1111/mec.12829

525 Rodrigues N, Vuille Y, Brelsford A, Merilä J, Perrin N (2016) The genetic contribution to sex

526 determination and number of sex chromosomes vary among populations of common frogs (Rana 527 temporaria). Heredity 117:25-32. doi:10.1038/hdy.2016.22

528

529 Roff DA (1992) Evolution of life histories: theory and analysis. Chapman and Hall, New York

530

531 Rozenblut B, Ogielska M (2005) Development and growth of long bones in European water frogs

532 (Amphibia: Anura: Ranidae), with remarks on age determination. J Morphol 265:304-317. doi:

$533 \quad 10.1002 /$ jmor. 10344

534

535 Ryser J (1996) Comparative life histories of a low-and a high-elevation population of the common frog

536 Rana temporaria. Amphibia-Reptilia 17:183-195. doi: 10.1163/156853896X00379

537

538 Saikkonen K, Taulavuori K, Hyvönen T, Gundel PE, Hamilton CE, Vänninen I, Nissinen A, Helander M 539 (2012) Climate change-driven species' range shifts filtered by photoperiodism. Nat Clim Chang 2:239540 242. doi: $10.1038 /$ nclimate 1430 
542 Schabetsberger R, Goldschmid A (1994) Age structure and survival rate in the Alpine newts (Triturus

543 alpestris) at high altitude. Alytes 12:41-47

544

545 Schneider DC (2001) The rise of the concept of scale in ecology. BioScience 51:545-553. doi:

$546 \quad 10.1641 / 0006-3568(2001) 051[0545: \operatorname{trotco}] 2.0 . c 0 ; 2$

547

548 Sinsch U (2015) Review: Skeletochronological assessment of demographic life-history traits in 549 amphibians. Herp J 25:5-13.

550

551 Sinsch U, Pelster B, Ludwig G (2015) Large-scale variation of size and age-related life-history traits in the

552 common frog: a sensitive test case for macroecological rules. J Zool 297:32-43. doi: 10.1111/jzo.12243

553

554 Smirina EM (1994) Age-determination and longevity in amphibians. Gerontology 40:133-146. doi:

$555 \quad 10.1159 / 000213583$

556

557 Stearns SC (1992) The Evolution of Life Histories. Oxford University Press, Oxford

558

559 Ter Schure AF, Larsson P, Merilä J, Jönsson KI (2002) Latitudinal fractionation of polybrominated

560 diphenyl ethers and polychlorinated biphenyls in frogs (Rana temporaria). Environ Sci Technol 36:5057-

561 5061. doi: 10.1021/es0258632

562

563 Van Buskirk J, Arioli M (2005) Habitat specialization and adaptive phenotypic divergence of anuran

564 populations. J Evol Biol 18:596-608. doi: 10.1111/j.1420-9101.2004.00869.x

565

566 Wagner A, Schabetsberger R, Sztatecsny M, Kaiser R (2011) Skeletochronology of phalanges

567 underestimates the true age of long-lived Alpine newts (Ichthyosaura alpestris). Herp J 21:145-148 
569 Wood SN (2006) Generalized additive models: an introduction with R. Chapman and Hall/CRC Press,

570 Boca Raton 
573 Fig. 1 Location of the study site in northern Finland (inserted map) and of the valley and hill sites in 574 Kilpisjärvi (larger map).

575

Fig. 2 Mean (A) SVL, (B) body mass and (C) age of female (white) and male (black) in common frogs,

577 Rana temporaria, from hill and valley sites

Fig. 3 Body size a function of age as estimated by GAMMSs (generalized additive mixed models) for the common frogs, Rana temporaria from: hill site, (A) SVL (mm) and (B) body mass (g) and valley site, (C) SVL (mm) and (D) body mass (g); gray shading shows $95 \%$ confidence intervals

Fig. 4 Length-at-age growth curves for the common frogs, Rana temporaria, derived with Von Bertalanffy method. (A) Hill (open circle, solid line) and valley (closed circle, dotted line) sites, and (B) females (open circle, solid line) and males (closed circle, dotted line)

587

Fig. 5 Age distribution of female and male common frogs, Rana temporaria, from hill $(n=134)$ and valley $(n=169)$ sites

591 Fig. 6 Yearly variation in age distribution of female and male common frogs Rana temporaria from the 592 hill site 
Table 3 The pairwise comparisons between site and sex on the SVL, body mass and age for the common frogs, Rana temporaria

\begin{tabular}{lcccc}
\hline & Estimate & $S E$ & $z$ & $p$ \\
\hline SVL (mm) & & & & \\
Valley Female - Hill Female & 16.799 & 0.717 & 23.443 & $<0.001$ \\
Hill Male - Hill Female & 3.675 & 1.001 & 3.671 & 0.001 \\
Valley Male - Hill Female & 10.702 & 0.819 & 13.067 & $<0.001$ \\
Hill Male - Valley Female & -13.124 & 0.850 & -15.435 & $<0.001$ \\
Valley Male - Valley Female & -6.097 & 0.626 & -9.744 & $<0.001$ \\
Valley Male - Hill Male & 7.027 & 0.938 & 7.490 & $<0.001$ \\
& & & & \\
Body mass (g) & & & & \\
Valley Female - Hill Female & 25.628 & 1.118 & 22.914 & $<0.001$ \\
Hill Male - Hill Female & 3.216 & 1.566 & 2.054 & 0.162 \\
Valley Male - Hill Female & 16.431 & 1.272 & 12.916 & $<0.001$ \\
Hill Male- Valley Female & -22.411 & 1.328 & -16.879 & $<0.001$ \\
Valley Male - Valley Female & -9.197 & 0.965 & -9.535 & $<0.001$ \\
Valley Male - Hill Male & 13.214 & 1.460 & 9.053 & $<0.001$ \\
& & & & \\
Age (year) & & & & \\
Valley Female - Hill Female & 5.713 & 0.263 & 21.736 & $<0.001$ \\
Hill Male - Hill Female & -0.451 & 0.368 & -1.224 & 0.603 \\
Valley Male - Hill Female & 2.516 & 0.299 & 8.411 & $<0.001$ \\
Hill Male- Valley Female & -6.164 & 0.312 & -19.750 & $<0.001$ \\
Valley Male - Valley Female & -3.198 & 0.227 & -14.108 & $<0.001$ \\
Valley Male - Hill Male & 2.966 & 0.343 & 8.643 & $<0.001$ \\
\hline
\end{tabular}


Table 5. Likelihood ratio test results comparing the von Bertalanffy model parameters between (1) hill and (2) valley sites, as well as between (3) female and (4) male common frog, Rana temporaria.

\begin{tabular}{llll}
\hline Hypothesis & Chi-sq. & $d f$ & $p$ \\
\hline Site & & & \\
$L_{\infty 1}=L_{\infty 2}$ & 1.92 & 1 & 0.166 \\
$k_{1}=k_{2}$ & 2.5 & 1 & 0.114 \\
$t_{01}=t_{02}$ & 0 & 1 & 1 \\
$L_{\infty 1}=L_{\infty 2}, k_{1}=k_{2}, t_{01}=t_{02}$ & 32.53 & 3 & $<\mathbf{0 . 0 0 1}$ \\
Sex & & & \\
$L_{\infty 3}=L_{\infty 4}$ & 0.02 & 1 & 0.888 \\
$k_{3}=k_{4}$ & 4.28 & 1 & 0.039 \\
$t_{03}=t_{03}$ & 13.23 & 1 & $<\mathbf{0 . 0 0 1}$ \\
$L_{\infty}=L_{\infty}, k_{3}=k_{4}, t_{03}=t_{03}$ & 33.84 & 3 & $<\mathbf{0 . 0 0 1}$ \\
\hline
\end{tabular}




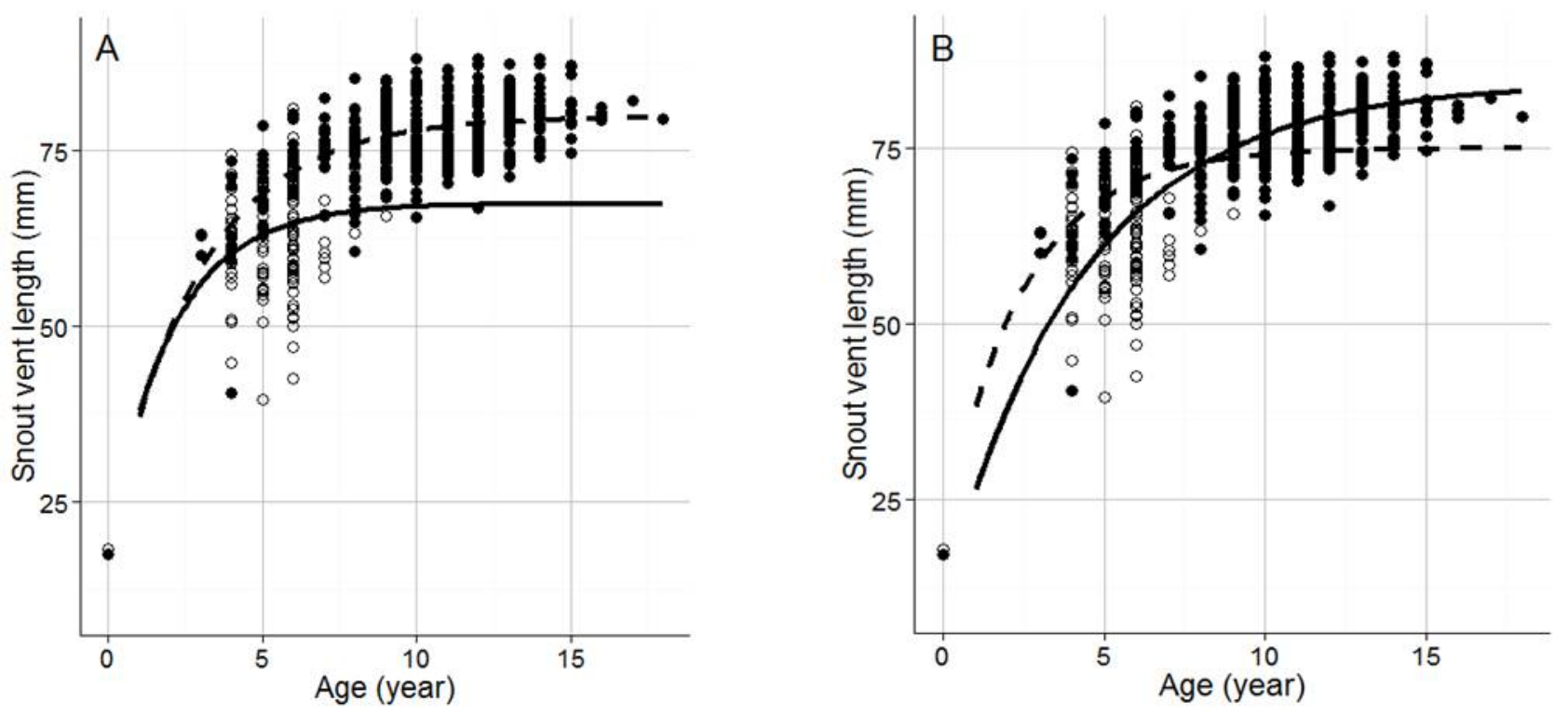



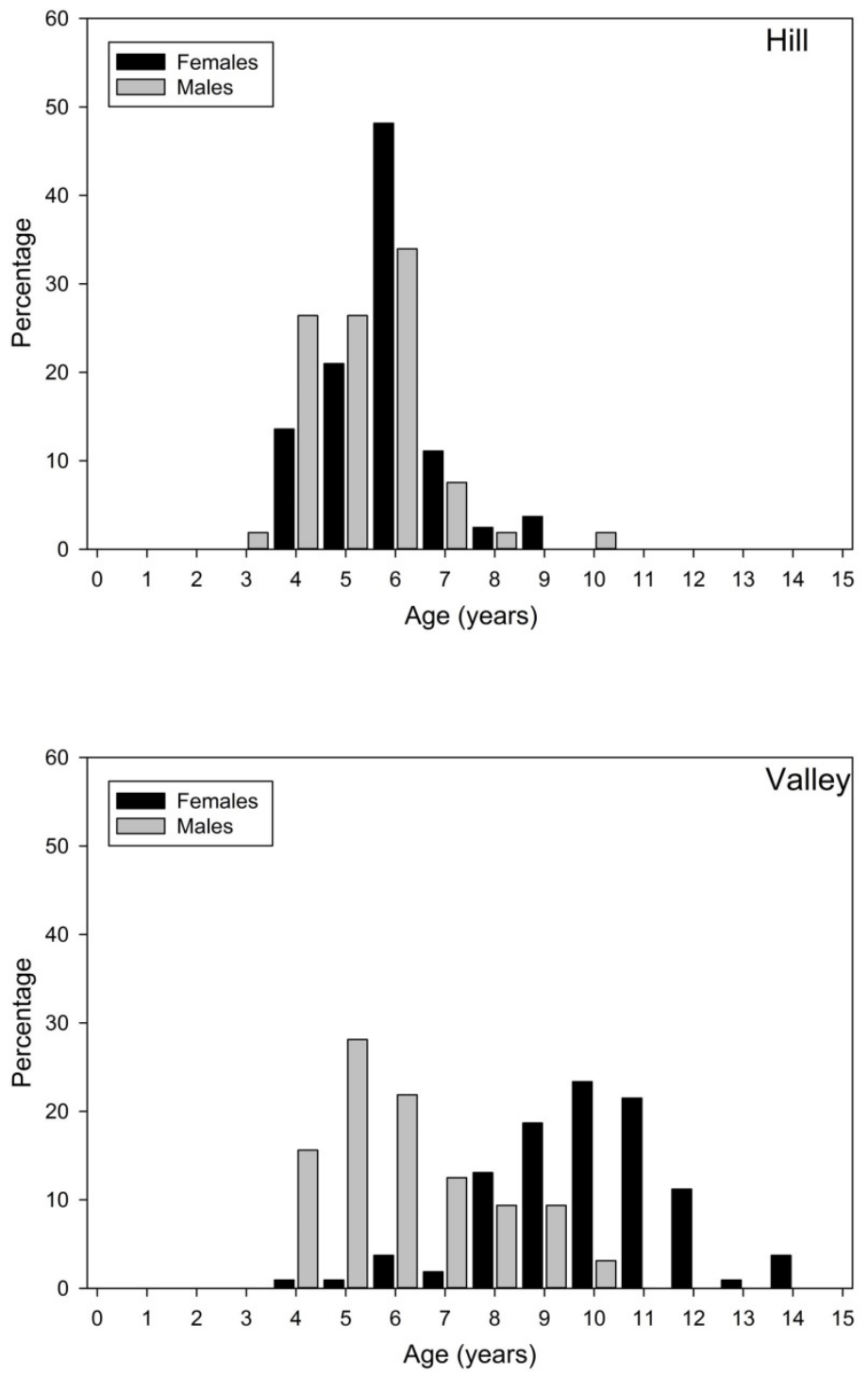